\title{
Investigation into Irradiation Effects in ODS Steels Using Ion Implantation and Micromechanical Testing.
}

\author{
E. M. Grieveson, S. G. Roberts \\ University of Oxford, Parks Road, Oxford, OX1 3PH, UK \\ Corresponding author email: eleanor.grieveson@materials.ox.ac.uk
}

\begin{abstract}
Oxide Dispersion Strengthened steels are materials for the first wall of proposed nuclear fusion reactors including DEMO. They contain a nanoparticle dispersion of $\mathrm{Y}_{2} \mathrm{O}_{3}$ which restricts dislocation motion. The particles act as low energy sites capable of trapping helium. The experiments reported here focus on the mechanical effects of ion implantation on a model $\mathrm{Fe}-\mathrm{Cr}$ alloy and an ODS equivalent. Samples were helium and iron ion implanted as a simulation of neutron damage and material transmutation. The main restriction of using ion implantation is the limited damage depth available in samples $(<3 \mu \mathrm{m})$, therefore nanoindentation was used to provide information on the surface hardness changes. Transmission Electron Microscopy was used to see how the dislocation structure within these test volumes changes with implantation.
\end{abstract}

Keywords - ODS, micromechanics, nanoindentation, ion implantation

\section{INTRODUCTION}

Nuclear fusion reactor materials have to be designed to withstand extreme environments, whilst remaining structurally and economically viable. The reactor first wall will be exposed to elevated temperatures $\quad\left(>550^{\circ} \mathrm{C}\right), \quad$ neutron damage ( 20dpa/year) and helium transmutation ( 10appm/dpa) [1].

Proposed materials for the first wall of fusion power plants, such as DEMO, include low activation steels based on iron-chromium alloys [2]. Oxide Dispersion Strengthened (ODS) $\mathrm{Fe}-\mathrm{Cr}$ alloys are being considered for their superior properties under these conditions, compared with conventional ferriticmartensitic alloys. ODS steels can be produced from low activation elements and they have good mechanical, corrosion and thermal properties [3]. They also demonstrate good resistance to microstructural change in irradiation environments. They are BCC steels containing a dispersion of nanoscale particles of yttria which restrict dislocation motion, increasing yield strength and creep strength [4]. The usual processing route is mechanical alloying of steel and $\mathrm{Y}_{2} \mathrm{O}_{3}$ powders, followed by compression through hot (isostatic) pressing or extrusion. The processing is crucial for optimising the final material properties [5][6].

Ideally test materials would be subjected to reactor conditions, however, neutron damage causes the materials to become radioactive and therefore all testing must be carried out in a controlled environment. This means that ion-implantation is often used as a simulation. Helium can be implanted to simulate the gas that would be introduced from the plasma, or transmuted from the wall material under reactor conditions, while self-ion implantation (i.e. Fe ions into an Fe substrate) is used to form damage cascades similar to those that would be induced by incident neutrons [7].

Ion-implantation, however, is limited to a thin, near-surface layer of the material $(\sim 1-10 \mu \mathrm{m}$ depending on the ion species and energies used) therefore it is necessary to perform all tests on the micro-scale. Nanoindentation makes it possible to accurately measure hardness changes in the surface of the implanted material.

\section{MATERIALS AND METHOD}

Tests were performed on two different materials:

- melt processed $\mathrm{Fe}-14 \mathrm{wt} \% \mathrm{Cr}$ - a model alloy provided by EFDA [8]

- extruded Fe ODS from CEA Saclay [9] $(\sim 14 \mathrm{wt} \% \mathrm{Cr}+\mathrm{W}, \mathrm{Mo}, \mathrm{Ti}, \mathrm{Y}, \mathrm{Si}, \mathrm{Ni} \& \mathrm{Mn})-$ an approximation to a commercial alloy.

Cut samples were ground with a final stage of 4000 grit silicon carbide paper and polished with 40nm colloidal silica - $10 \%$ hydrogen peroxide solution on a chemo-mechanical polishing cloth. This method has been shown to give a high quality surface finish, free from damage [10].

Implantations were planned using SRIM software [11] to predict the ion range in the materials, giving fairly uniform distribution to the required depth.

One set of samples was He ion implanted at the Surrey Ion Beam Centre at $300^{\circ} \mathrm{C} \pm 10^{\circ} \mathrm{C}$ to $\sim 2000$ appm He in a flat profile to $\sim 3 \mu \mathrm{m}$ depth. This was done with ten successive implantations at 1.8, 1.6, $1.4,1.2,1.0,0.8,0.6,0.4,0.3 \& 0.2 \mathrm{MeV}$ with $\mathrm{He}^{+}$ ions. Bulk samples were mounted on a stainless steel polishing plate and the temperature was recorded through a thermocouple mounted on the surface next to the samples. A second set was dual beam implanted 
at JANNUS, CEA Saclay, with 2000appm He and Fe to cause 3 dpa damage also to $\sim 3 \mu \mathrm{m}$ depth at $300^{\circ} \mathrm{C}$. This used $\mathrm{Fe}^{8+}$ at $24 \mathrm{MeV}$ with spun aluminium degrader foils of $5,3.8,2.8,1.6 \& 0.8 \mu \mathrm{m}$ and an empty slot on one beam line. The second beam line used $\mathrm{He}^{+}$at $2 \mathrm{MeV}$ with degraders of 5, 4, 3, 2 \& $0.8 \mu \mathrm{m}$ and an empty slot.

Nanoindentation was performed using an MTS Nanoindenter XP with a Berkovich tip and continuous stiffness measurement, allowing hardness as a function of depth to be measured. Each line on the graphs is an averaged hardness over 20 indents, with the error bars showing one standard deviation. Each material was tested and calibrated in a set covering all implantation conditions. The indentations for hardness testing were made to a depth of $3000 \mathrm{~nm}$ at a loading rate of $5 \mathrm{nms}^{-1}$. The indentations for Transmission Electron Microscopy (TEM) imaging were made to $100 \mathrm{~nm}$ depth.

Samples for TEM imaging were cut from the material, thinned using a Zeiss Auriga FIB-SEM and then imaged on a JEOL JEM-2010 at 200kV.

\section{RESULTS AND DISCUSSION}

The graphs 1a and 1b show that the ODS material has a higher baseline hardness than its non-ODS equivalent.

Implantation with 2000appm $\mathrm{He}$ causes a significant increase in hardness - this change is more pronounced in the non-ODS material. Also visible on the graphs (most noticeable in the $\mathrm{Fe}-14 \mathrm{wt} \% \mathrm{Cr}$ ) is a shoulder in the hardness around the $500 \mathrm{~nm}$ depth mark on the 2000appm He line.

All the curves converge to their respective baseline hardnesses at around 2000nm depth. Although the implantations are to a depth of 3000nm, the plastic zone size of the indent at depths below 2000nm will make the effects of the implanted ions negligible [12].

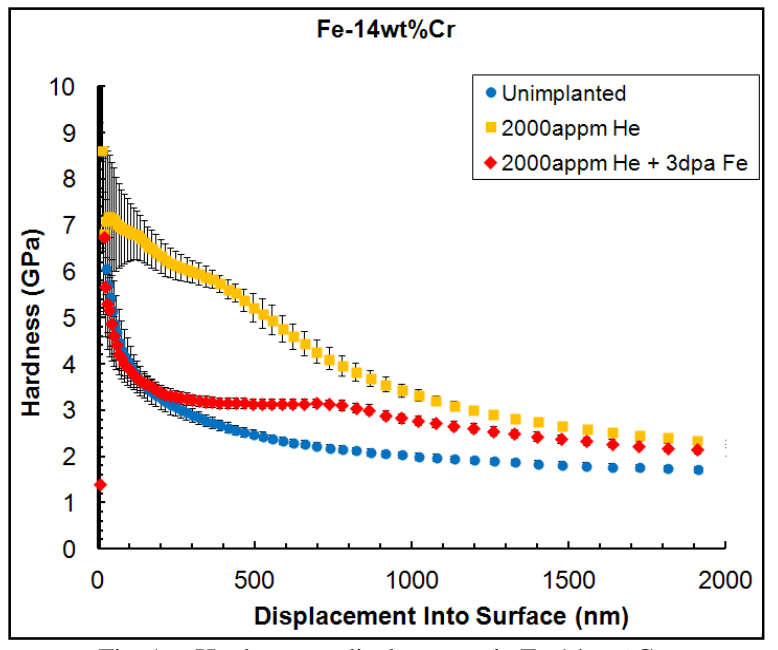

Fig. 1a Hardness vs. displacement in $\mathrm{Fe}-14 \mathrm{wt} \% \mathrm{Cr}$

\section{A. 2000 appm He}

The hardness changes in materials are due to the He forming defects in the lattice, so restricting dislocation motion. As $\mathrm{He}$ is implanted, it is most likely to initially fill vacancies (generated by ion collisions) in the ferritic matrix. Above a critical concentration, $\mathrm{He}$ starts to collect into bubbles throughout the matrix, which causes significant hardening. In $\mathrm{Fe}$ alloys, the hardness results indicate that this concentration is >100appm He [13]. At 2000appm He, where significant hardening occurs, a bubble population has been seen in TEM images take of these materials [14].

In ODS materials, the nanoparticles also provide low energy locations for the helium to collect and form fine, well dispersed, bubbles. This reduces bubble population and therefore the hardening effects in the material. It is also expected to reduce the amount of helium migrating to the grain boundaries so reducing the grain boundary embrittlement.

\section{B. 2000 appm $\mathrm{He}+3$ dpa Fe}

It is interesting to observe, however, that in the dual-beam implanted samples the hardening effect of the $\mathrm{He}$ is lessened compared to the $\mathrm{He}$ only implantation, and in the case of the ODS material, apparently reversed - i.e. the hardness is lower after implantation.

As the Fe ions are implanted they cause damage cascades in the lattice, simulating the primary knockon atom of an incident neutron. The "collision cascade" thus produced, results in residual point defects and prismatic dislocation loops [15]. A possible explanation for the decreased hardening in the dual beam experiment is that the implanted $\mathrm{He}$ is attracted to these defects and so there is less spread throughout the lattice to cause the hardening that was seen in the materials implanted with $\mathrm{He}$ alone. The reason for the apparent softening in the ODS material is unclear.

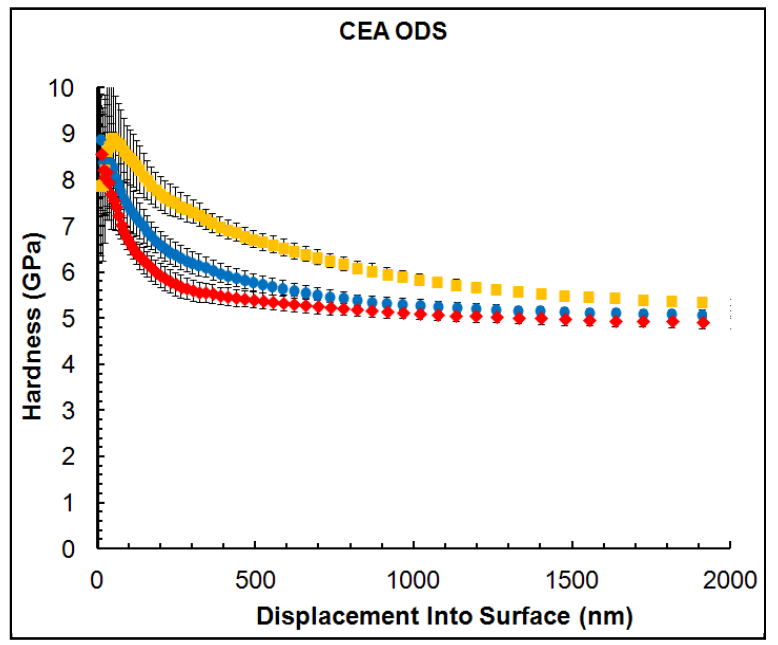

Fig. 1b Hardness vs. displacement in CEA ODS 


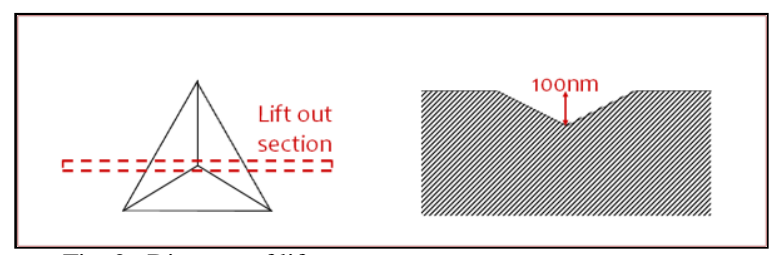

Fig. 2 Diagram of lift out geometry
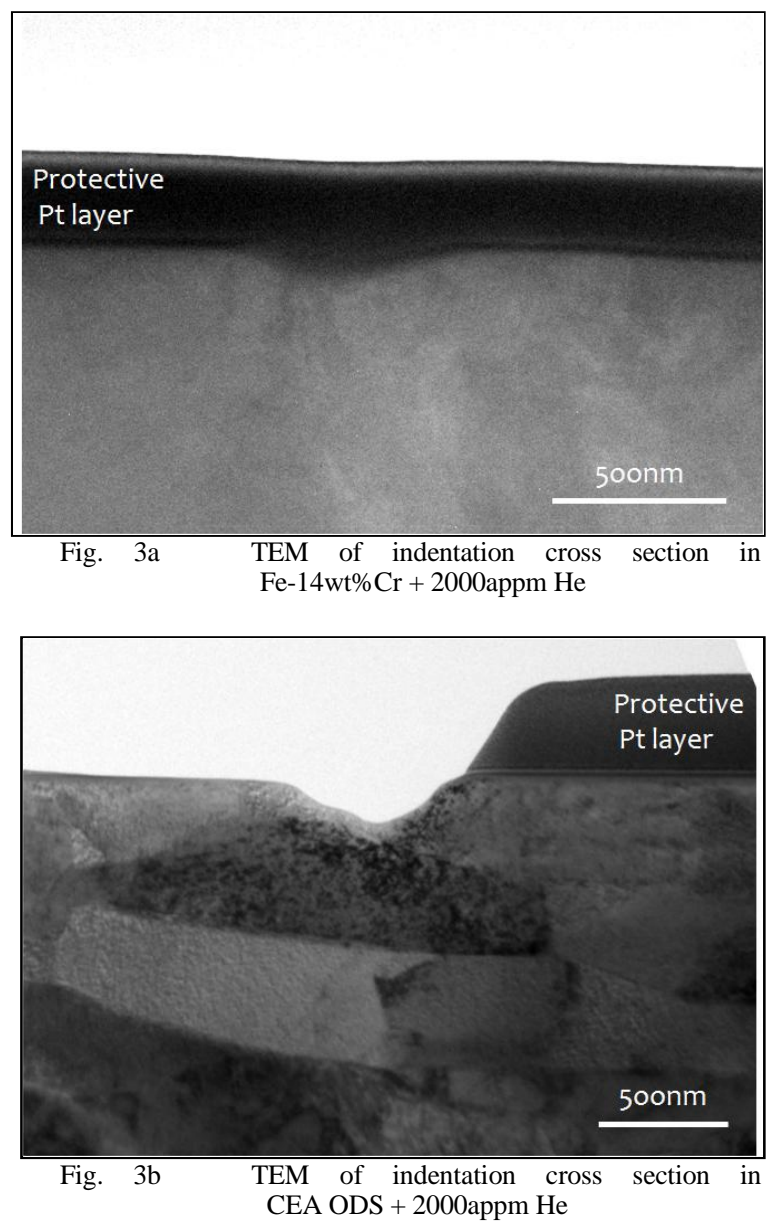

\section{TEM of Indentation Lift-outs}

In order to understand the mechanical property changes, FIB-cut lift-outs were made across shallow nanoindentations (Figure 2).

Preliminary images $3 a$ and $3 b$ show higher density dislocation structures beneath the indentations in the ODS materials (3b) than the non-ODS (3a). In 3a slight darker bands can be made out spreading from the indentation showing the location of the damaged material. In $3 b$ the dislocation structures are much more visible as dark spots below the indentation. This is possibly due to the dislocation interactions with the ODS particles, but further lift out samples with varying TEM diffraction conditions are required to draw any more definite conclusions.

\section{CONCLUSION}

Implantation of high concentrations of helium into iron based alloys has a hardening effect. In ODS variants of these alloys the hardening effect is observed to be less. This is possibly due to the interaction of the ODS particles with the implanted helium.

When the samples are dual implanted with helium and iron ions the hardening effect is significantly changed, possibly due to helium/iron damage interactions.

In order to fully investigate the effects of the implantations and the reason for the differences in hardness changes, further experiments are in progress.

\section{ACKNOWLEDGMENTS}

Authors thank the following for financial support: EPSRC (Programme Grant EP/H018921/1), RollsRoyce Plc, The Worshipful Company of Founders, The Armourers \& Brasiers' Gauntlet Trust and Corpus Christi College, Oxford.

We gratefully acknowledge our materials were provided by Benjamin Fournier at CEA Saclay (Commissariat à l'énergie atomique et aux energies alternatives) and EFDA (European Fusion Development Agreement).

\section{REFERENCES}

[1] H. Bolt, V. Barabash, W. Krauss, J. Linke, R. Neu, S. Suzuki, N. Yoshida, Materials for the plasma-facing components of fusion reactors, Journal of Nuclear Materials, 329-333 (2004) pp 66-73

[2] A. Kohyama et al., The development of ferritic steels for DEMO blanket, Fusion Engineering and Design, 41 (1998) pp. 1-6

[3] H. Kishimoto, K. Yutani, R. Kasada, A. Kimura, Helium cavity formation research on oxide dispersion strengthening (ODS) ferritic steels utilising dual-ion irradiation facility, Fusion Engineering and Design 81 (2006) pp 1045-1049

[4] M.J. Alinger, G.R.Odette, D.T. Hoelzer, The development \& stability of Y-Ti-O nanoclusters in mechanically alloyed Fe$\mathrm{Cr}$ based alloys, Journal of Nuclear Materials, 329-333 (2004) pp 382-386

[5] S. Kavithaa, R. Subramanian, P.C. Angelo, Yttria dispersed 9Cr martensitic steel synthesized by mechanical alloying hot isostatic pressing, Transactions of The Indian Institute of Metals, 63(1) (2010) pp 67-74

[6] C Suryanarayanaa, E Ivanov, V.V Boldyrev, The science and technology of mechanical alloying, Materials Science and Engineering: A, 304-306 (2001) pp 151-158

[7] G.S. Was, Fundamentals of radiation materials science (Metals and alloys), Springer 2007

[8] CEA Saclay (Commissariat à l'énergie atomique et aux energies alternatives)

[9] EFDA (European Fusion Development Agreement)

[10] D.E.J. Armstrong, A.J. Wilkinson, S.G. Roberts, Mechanical properties of ion-implanted tungsten-5wt\% tantalum, Physica Scripta, vol. T145 (2011), 014076 
[11] R. Webb, M. Bailey, C. Jeynes, G. Grime, SRIM - The stopping and range of ions in matter, Nuclear Instruments and Methods in Physics Research Section B: Beam Interactions with Materials and Atoms, Volume 268, Issues 11-12 (2010) pp 1818-1823

[12] M. Mata, O. Casals, J. Alcala, The plastic zone size in indentation experiments: The analogy with the expansion of a spherical cavity, International Journal of Solids and Structures, 43 (2006) 5994-6013
[13] D. Kramer, H.R. Brager, C.G. Rhodes, A.G. Pard, Helium embrittlement in type 304 stainless steel, Journal of Nuclear Materials, 25(2) (1968) pp 121-131

[14] C. Burrows, University of Oxford, Unpublished work

[15] D.J. Bacon, Y.N. Osetsky, Dislocation-Obstacle Interactions at Atomic Level in Irradiated Metals Mathematics and Mechanics of Solids, 14 (1-2) (2009) pp 270-283 